\title{
ANÁLISE DA PROPORÇÃO DE IDOSOS COM LIMITAÇÃO DE MOBILIDADE FÍSICA NO BRASIL E NO ESTADO DA PARAÍBA: USO SISTEMA (SISAP-IDOSO)
}

\section{Jordane Reis de MENESES JUNIOR ${ }^{1}$}

${ }^{1}$ Graduado em Educação Física/Universidade Federal da Paraíba, Brasil. E-mail: jordanejunior@gmail.com

Introdução: $O$ envelhecimento é um processo de perdas funcionais que podem dificultar no desempenho de alguns gestos e de algumas atividades do dia e fisiológicas, decorrente de determinadas doenças e pela falta de atividade física, que vem crescendo em todo Brasil, gerando intensas mudanças no perfil da sociedade e nos sistemas de saúde. A prática da atividade física é uma das melhores formas de retardar o envelhecimento celular e na aptidão física dos idosos. É possível supervisionar a proporção de idosos com limitação de mobilidade física por meio da consulta ao Sistema de Indicadores de Saúde e Acompanhamento de Políticas do Idoso (SISAP-Idoso) que é um instrumento desenvolvido pela Coordenação de Saúde da Pessoa Idosa (COSAPI) do Ministério da Saúde e da Fundação Oswaldo Cruz (Fiocruz). Objetivo: Analisar a proporção de idosos com limitações de mobilidade física no período de 1998 a 2008 no estado da Paraíba e no Brasil. Metodologia: Trata-se de um estudo de caso, descritivo, com cortes quantitativos que propõem descrever a proporção de idosos de 60 anos ou mais com limitações de mobilidade física na Paraíba e no Brasil. Os dados coletados nesse estudo foram extraídos da Pesquisa Nacional por Amostra de Domicílios e da Pesquisa Nacional de Saúde (PNAD) publicados no Sistema de Indicadores de Saúde e Acompanhamento de Políticas do Idoso (SISAP-Idoso) de domínio público. Conclusão: Com embasamento nos dados colhidos no período de 1993, 2003 e 2008, foi possível alcançar algumas análises na proporção de idosos que possuem mobilidade física prejudica na Paraíba e no Brasil. A Paraíba apresentou uma proporção nos anos 1998, 2003 e 2008: 27,90\%, 26,90, 24,20 respectivamente. Sendo possível observar que os números de idosos com limitações de mobilidade física tem diminuído com o passar dos anos. As proporções apontadas para o Brasil, no mesmo período, são de 23,10\%, 21,90, 23,20 mostrando que as limitações de mobilidade física nos idosos vem sendo reduzida, apesar de em 2008 apresentar um pequeno aumento em relação aos outros anos investigados. Os resultados nós mostram que a população brasileira e paraibana idosa, tem melhorado os cuidados com a saúde. As ações de promoção de saúde e de monitoramento do sedentarismo em todos os níveis da atenção tem melhorado a qualidade de vida dos idosos. Monitorar e avaliar podem instrumentalizar os administradores para obterem elementos para o planejamento de novas ações nas políticas de saúde, prevenção e na promoção da saúde por meio da atividade física para os idosos.

Palavras-chave: Atividade Física, Indicadores Básicos de Saúde, Saúde do Idoso. 